\title{
A REVIEW PAPER ON: ORGANIC LIGHT-EMITTING DIODE (OLED) TECHNOLOGY AND APPLICATIONS
}

\author{
Nikhil Sain \\ Department of E.C. \\ Arya Institute of engineering \& Technology \\ Jaipur, Rajasthan, India
}

\begin{abstract}
Organic LEDs is a semiconductor device, in solid state containing a conducting an emissive layer between two electrodes to create light with application of electricity. The concept of hole or electron in limited electroluminescence OLED devices has made it renowned in display technology. In dispay light emitted diode (LEDS) and liquid crystal diode ( LCDS) are used but they have certain problem so we descoverd OLED to overcome the problem associated with them.
\end{abstract}

Keywords: AMOLED, LED, OLED, PMOLED

\section{INTRODUCTION}

An OLED is a thin-film device in a solid state based on electroluminescence. OLEDs replaced CRTs or LCDs in the last two decades. OLED is a LED where the emissive electroluminescence layer is organic emitting light responding to an electric current [2]. OLED is two type Based on small molecules and polymers. OLED displays can either be PMOLED or AMOLED. An OLED works absence of a backlight. An OLED has many advantages over LCD. The concept of hole or electron limited electroluminescence in OLEDs decrease the operating voltage [8-10] when improving the light output and efficiency. OLEDs include organic resonant tunnelling diodes, organic phototransistors, organic photodetectors and organic photo voltaic cells.

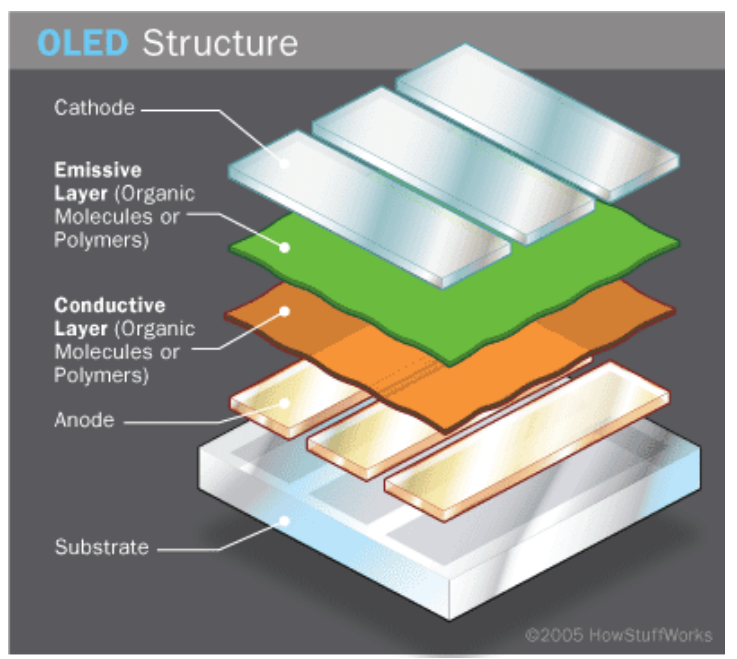

Fig. 1: Basic Structure Of Oled [122]

\author{
Deepesh Sharma, Priya Choudhary \\ Department of E.C. \\ Arya Institute of engineering \& Technology \\ Jaipur, Rajasthan, India
}

An OLED is a solid-state semiconductor device which is $100-500 \mathrm{~nm}$ thick and it consists of a conducting layer and an emissive layer between two electrodes and placed on a substrate. OLEDs are double charge injection devices, requiring continuous supply of both electrons and holes to electroluminescent material between two electrodes. In the two layers based OLED, electrons injected from the cathode in LUMO (conduction band) and holes are injected from the anode in HOMO (valence band). In three layers based OLED, the conductive layer is replaced by electron-transport layer (ETL) and holetransport layer (HTL).

\section{HISTORY}

Electroluminescence in organic materials was first observed in 1950 applying high voltages in air to acridine orange. Ohmic dark-injecting electrode was developed by Martin Pope in NY University in 1960. They explained needs for hole and electron electrode contacts. DC electroluminescence was first observed under vacuum on one crystal of anthracene by Pope's group. He implied in 1965 that when external E.F. is absent, electroluminescence in anthracene crystals is generated by recombination of electron and hole. Double injection recombination electroluminescence was produced in an anthracene crystal through hole and electron electrodes by W. Helfrich and W. G. Schneider of the National Research Council in Canada in 1965. They reported about electronic excitation at contacts between graphite molecules and anthracene particles. Electro luminescence of polymer films was observed by Roger Partridge at the National Physics Laboratory in the UK. It had a film of poly (n-vinyl carbazole) between two charged injecting electron. recombination and light emission in middle of the organic layer, leading to OLED research and device production.

J.H. Burroughs at the Cavendish Laboratory in Cambridge culminated with polymer electroluminescence in 1990 reporting a green light-emitting polymer device.

\section{MATERIALS AND STRUCTURE}

OLED is a electronic device consist of thin-film, monolithic semi-conductor device which emits light when voltage is applied to it. When electric filed is applied to organic materials, various ways of light are 


\section{International Journal of Engineering Applied Sciences and Technology, 2020 \\ Vol. 4, Issue 11, ISSN No. 2455-2143, Pages 587-591 \\ Published Online March 2020 in IJEAST (http://www.ijeast.com)}

generated. This is known as EL (electroluminescence). OLED has a series of vacuum deposited, organic thin films between two film conductors. An OLED device has hole-transporting layer (HTL) and electrontransporting layer(ETL)[26,27] sandwiched between two electrodes. OLEDs are different from inorganic LEDs for the fundamental reasons. Firstly, films of small molecules for OLEDs are wide energy gap semiconductors. Secondly singlet and triplet excitons which are neutral molecules in excited state are generated by recombination of charge and emission because of radiative transitions. Two types of electroluminescent materials[28] are smallmolecules(SM-OLED) and polymers (PLED) [2942,17- 19].

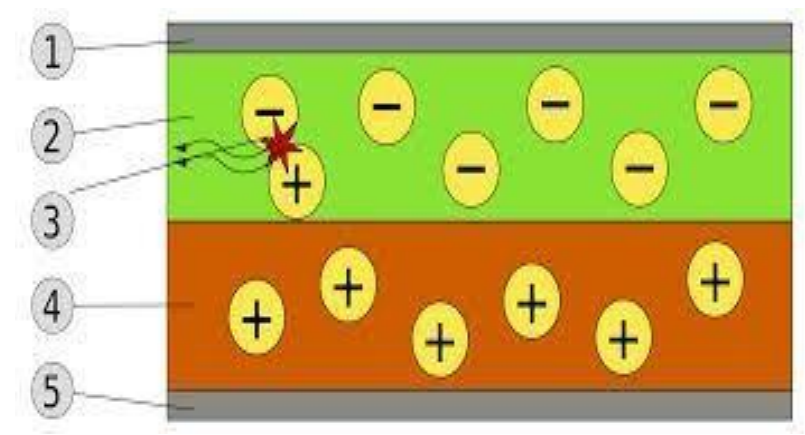

Fig. 2: Bilayer Oled: 1. Cathode (-), 2:

Emissive Layer, 3: Emission Of Radiation, 4: Conductive Layer, 5: Anode (+)

OLED consist of following components:-

1. Substrate- the substrate [43] in an OLED may be a plastic foil or even a glass. If light emitted passes through substrate, such OLED devices are named bottom emission devices.

2. Anode- indium tin oxide(ITO) is the anode component. It is a sufficient conductor having high work function promoting injection of holes into the HOMO levels.[45-47]

3. Hole-transport layer (HTL) - The p-type materials for OLED are TPD and NPB. [49,50]

4. Emissive layer- the emissive layer of an OLED consists of organic plastic molecules like polyfluorine holes are more mobile than electrons in organic semiconductors. The colour of the light produced varies to type of organic molecule used.

In organic electroluminescence, the processes involved are charge injection, charge transportation, exciton formula and light emission.

\section{OLEDS TYPES}

Depending on the type of manufacture and the nature of their application, OLEDs are classified into:-

\section{Passive- matrix OLED (PMOLED):-}

PMOLEDs [64] basically consist of organic layers and anode strips in perpendicular order to the cathode strips. Intersection of strips makes pixels where light is emitted. The brighter the pixel the more amount of current is applied. External circuit provides current to some strips to turn on or off the pixels. They are easy and cheap but use more power than other OLED but still less power than LCD and LED. They are limited in size and resolution. They have wide applications in MP3 player, cell phones displays.

\section{Active matrix OLED (AMOLED) :-}

AMOLEDs [65-72] include complete layers of cathode, organic components and anode. The layers of anode consists of TFT (thin film transistors) $[73,75]$ in parallel to form a matrix, which helps in switching each pixel to it's on or off state as required hence, forming an image. When the pixels are not needed, they turn off or a black image on display occurs. This is least power consuming type and has quick refresh rates. They are best used in computer monitors, electronic signs or big TV screens.

\section{Transparent OLEDs}

TOLEDs have only components which are transparent as the name suggests like substrate, cathode and anode. When a display of such kind is turned on, light is allowed to pass in both directions. It is applied in both active and passive matrix categories.

Since they consist of transparent parameters on both sides, they can form displays with top and bottom emitting. It is widely used in head-up displays, laptops and smart windows. TOLEDs enabled features like transparency, enhanced constant ratio and multi-stacked devices. TOLEDs are applied into a rear-view mirrors and transmitters or had-up information systems.

\section{Top-emitting OLED}

Such OLEDs have either an opaque or reflective substrates. They are preferred for active-matrix applications due to the reason of them being easily integrated with a non-transparent transistor backplane [74]. Top-emitting OLED displays are used by manufacturers in smart cards.

\section{Foldable OLEDs}

FOLEDs have substrates out of flexible metallic foils or plastics. They have advantages of flexibility, durability and lightweight quality. Since the material has high strength, it decreases breakage and hence, are used in GPS devices, mobilephones and big curved screen TVs. FOLEDs have many added merits like it offers better picture resolution and faster response time. It finds its applications in mobile phones, GPS receiver and OLED display into it.

\section{White OLEDs}

White OLEDs are characterised by true-colour qualities of incandescent lightning and emit brighter white light than that by uniform and energy efficient fluorescent lights and incandescent bulbs. Since they are manufactured in big sheets, are cost-effective and consumes less power, they replace fluorescent lamps and could decrease energy costs for lightning. It is best suited for car lightning. White OLEDs are thin and light-weight making vehicles more 


\section{International Journal of Engineering Applied Sciences and Technology, 2020 \\ Vol. 4, Issue 11, ISSN No. 2455-2143, Pages 587-591 \\ Published Online March 2020 in IJEAST (http://www.ijeast.com)}

compact and efficient.

\section{PHOLEDs}

PHOLEDs decreases heat generation. Thus, we find its application in a large-sized OLED TV or lamps. Because it is energy- efficient, PHOLEDs can decrease temperature substantially. It also reduces the quantity of air conditioning needed to remove the produced heat making such a technology a necessary element in -greenll [76] or environmental building strategy. PHOLEDs have applications in computer monitors and TV screens or light panels.

\section{COLOUR GENERATION}

Many attempts have taken place to generate full-colour OLED displays i.e. in fabricating red, blue and green pixels. The complication lies in patterning of pixels and in attaining constantly emitting light in a ratio in correspondence to white colour [77]. But it depends on the intrinsic performance of materials.

\section{Red, green and blue pixels:-}

The drawbacks include the difficulties of deposition of individual pixels and short lifetime of blue-emitting materials [76].Yet, they have good optical performances.

\section{Blue emitter and colour converters:-}

This technique involves only one colour of luminescent material thus, is simple. Blue- emitter structure is first placed over substrate and a red and green colour converter film is then deposited onto the display. Due to losses induced, the blue emitters must have high efficiency, limiting its lifetime [91,92].

\section{White emitter and colour filters:-}

Patterning of pixels is not required. Two or more luminescent materials are used to build white light [93] which turns into red, green and blue because of a colour filter film [94,95]. Through photolithography techniques, both the colour filters and colour conversion films can be patterned for LCDs. The drawbacks include filtering or efficiency of the colour conversion.

At Princeton university, SOLED (stacked OLED) $[96,97]$ was invented having red, green and blue emitters in each pixel separated by transparent contacts. It has improved resolution.one demerit is brightness reduction.

\section{DISPLAY TECHNOLOGY}

OLEDs have been giving a tough competition to liquid- crystal displays (LCDs). The attributes of an LCD or an OLED display compared with cathode-ray tube (CRT) is layout of its active area having pixels forming images in an off or on state. An OLED pixel is an emissive device which can be turned off and be black. A liquid crystal pixel is a Transmissive device not allowing complete occultation of backlight.

\section{PASSIVE MATRIX DISPLAYS}

A pixel is basically the crossover area of linear electrodes positioned on each side of liquid crystal or of emissive material in OLED. In such case, each line is selected in period of $\mathrm{T} / \mathrm{N}$ where $\mathrm{T}$ is frame time and $\mathrm{N}$ is number of lines of display. Then, next line is selected. Slow Response transducer (LCDs) alters the display contrast and can demonstrate for displays of 100-200lines. Fastresponse transducers(OLEDs) can work for display of 240 lines, leading to high power consumption and damage of the pixels. Passive matrix OLED (PMOLED) is attractive due to simple device construction.

\section{ACTIVE MATRIX DISPLAYS}

In this technique, each pixel is characterised by its own electrode and driven by TFT circuitry and capacitors. the LCD or OLED which acts as an active "material is deposited on top of active matrix circuitry and the counter electrode which is not patterned.it is used in flat panel displays(FPDs) for large and high-resolution devices.

\section{FABRICATION}

OLEDs are attractive because of their efficient film forming properties and can be easily applied over big surfaces using simple and economically viable coating techniques like inkjet printing [98]. The basic part of manufacturing OLEDs is application of the organic layers to the substrate. This can be done in the following ways:-

\section{Vacuum thermal evaporation and shadow masking} In this method, small organic Molecules are generally evaporated and condensed as thin films on cooled substrates. A 20-100 micrometres thick shadow mask is kept on crucible and substrate is set on top of it. When stack of layers is deposited, they are shifted by one pixel to next set of pixels. The limitations of this complicated method are the need of accuracy and handling of shadow masks. The demerits involve the high cost and poor deposition efficiency. Yet, it provides well controlled and construction of complex multi-layer structure. The high efficiencies of OLEDs is high flexibility $[99,100]$ in design and thus, forming charge blocking layers.

\section{Organic vapour phase deposition (OVPD)}

It's a technique which is very efficient as well as cheaper. In low pressure, hot-walled chamber, a gas shall transport heated organic molecules to cooled substrates where it condenses to thin films. This heightens the efficiency and decreases the cost.

\section{Transfer- printing}

Light adhesive polymer layers are placed to increase resistance to particles. OLED layers are applied to anode layer through conventional vapour deposition methods. It can print on target substrates till $500 \mathrm{mmX} 400 \mathrm{~mm}$. it is used for fabrication of OLED / AMOLED displays. 


\section{International Journal of Engineering Applied Sciences and Technology, 2020 \\ Vol. 4, Issue 11, ISSN No. 2455-2143, Pages 587-591 \\ Published Online March 2020 in IJEAST (http://www.ijeast.com)}

\section{Inkjet printing}

This technology involves a solution which is dispensed onto substrate using inkjet nozzles. Drops of few Pico litres are injected at inkjet head. It is a very commonly used technique which is the cheapest. It has very high efficiency and decreases the cost of OLED manufacturing. With this, an OLED can print on very large films for big displays like dashboards, TV screens. The Inkjet printing [112] technique in OLED has been used by Seiko Epson and Cambridge display technology since 1996.

\section{ADVANTAGES}

Organic materials like OLEDs have wide scope for electronics applications due to many advantages like:-

1. Very thin solid-state device.

2. Lightweight- the substrates are shatter resistant unlike glass displays of LCD devices.

3. High luminous power efficiency [113-116] -an inactive OLED element does not generate light or consumes power, hence allowing true blacks.

4. Fast response time making entertaining animationsLCDs reach as low as $1 \mathrm{~ms}$ response time for their fastest colour transition.

5. Wide-viewing angle- OLEDs enable wider viewing angle in comparison to LCDs because pixels in OLEDs emit light directly. The colours appear correct.

6. Self-emitting hence, removing requirement of a backlight source.

7. Colour tuning for full colour displays

8. Flexibility - OLED displays are fabricated on flexible [117] plastic substrates producing flexible organic LEDs.

9. Cost advantages over inorganic devices- OLEDs are cheaper in comparison to LCD or plasma displays [118].

10. Low power consumption

Because OLEDs don't require backlighting, they consume much less power than LCDs. OLEDs are easier to produce and since they are plastics, they can be made into large and thin sheets. OLEDs refresh quicker than LCDs hence, video images are more realistic and updated.

\section{APPLICATIONS}

OLEDs have wide variety of uses which we come across in our daily life. Some significant applications of OLEDs are:-

1. To build digital displays in TV screens $[119,120]$, cell phones, PDAs, monitors, car radios, digital cameras.

2. OLEDs have wide applications in lightning like Philips made OLED samples with name _LUMIBLADE'. Similarly, novaled AG based in Germany developed OLED desk lamps named -victoryll in 2011.

3. It is used in watches. Fossil (JR-9465) and Diesel (DZ- 7086) used OLED displays.

4. In 2014, an OLED panel with life of 30000 hours twice that of conventional OLED panels was developed by MCC of the Mitsubishi Chemical Holdings.

5. OLEDs have replaced CRTs (Cathode Ray Tubes) or LCDs (Liquid Crystal Display).

6. Samsung electronics generated full-colour AMOLED displays on the basis of a white emitter.

7. Top-emission structures have merits for production of OTFT- OLED displays [121].

\section{CONCLUSION}

The production of OLEDs have been one of the most promising technology due to their advantages over LCDs like high contrast ratio and wide viewing angles like 170 degrees or fast response time. OLED has been hailed as -the first discovery since Edison $\|$.

Research and development in OLEDs have resulted in future applications like dashboards and in flexible displays. Video images seem more realistic and updated.

OLED till nowl has many challenges like heavy production costs, longevity issues for colours or sensitivity to water vapour. In the years 2005 and 2006, the breakthrough of OLED technology in displays had revenue of $\$ 832$ million and $\$ 1.2$ billion respectively.

\section{REFERENCES}

[1] N.C. Greenham, R.H. Friend, -In Solid State Physicsll, in Academic Press, New York, London, 1995, 2-150.

[2] J. Kalinowski, -Electroluminescence in organicsll,in Journal of Physics D: Applied Physics 32 (1999) 179250.

[3] S. Miyata, H.S. Nalwa, -Organic Electroluminescent Materials and Devicesll, in Gordon and Breach, Amsterdam, 1997.

[4] J. Shinar, -Organic Light-emitting Devicesll, in Springer, Berlin 2004.

[5] J. Kalinowski,-Emission Mechanisms in Organic LightEmitting Diodesl, in Organic Electroluminescence, Taylor \& Francis, Boca Raton, 2005.

[6] J. Godlewski, M. Obarowska,-Organic light emitting devices\|, inOpto-Electronics 15/4 (2007) 179-183.

[7] Pfeiffer M, Leo K, Zhou X, Huang JS, Hofmann M, Werner $A$ and Blochwitz-Ninoth J, -Very-lowoperating-voltage organic light-emitting diodes using a p-doped amorphous hole injection layerl, in Org Electron 4:89 (2003).

[8] J. Huang, M. Pfeiffer, A. Werner, J. Blochwitz, K. Leo, -Low- voltage organic electroluminescent devices using pin structuresl, in Applied Physics Letters 80 (2002) 139-141.

[9] W. Hu, K. Manabe, T. Furukawa, M. Matsumura, -Lowering of operational voltage of organic 


\section{International Journal of Engineering Applied Sciences and Technology, 2020 \\ Vol. 4, Issue 11, ISSN No. 2455-2143, Pages 587-591 \\ Published Online March 2020 in IJEAST (http://www.ijeast.com)}

electroluminescent devices by coating indium-tinoxide electrodes with a thin $\mathrm{CuOx}$ layer\|, in Applied Physics Letters 80 (2002) 2640-2643.

[10] M. Pope, H. Kallmann, P. Magnate, -Electroluminescence in organic crystals\|, in Journal of Chemical Physics 38 (1963) 2042- 2043.

[11] J. Kalinowski, J. Godlewski, R. Signerski, -Electroluminescence in tetracene crystalsl, in Molecular Crystals and Liquid Crystals 33 (1976) 247-259.

[12] R.H. Partrige, -Electroluminescence from polyvinylcarbazole films\|, in Polymer 24 (1983) 733762.

[13] Braun D., Heeger A.,\| Visible light emission from semiconducting polymer diodes $\|$, in J. Appl. Phys. Lett., 58 (1991) 1982.

[14] Kraft, A., Grimsdale A. C., Holmes A. B., Angew.,\|Electroluminescent Conjugated PolymersSeeing Polymers in a New Lightl, in Chem. Int. Ed., 37 (1998) 402.

[15] Friend R. H., Gymer R. W., Holmes A. B., Burroughes J. H., Marks

R. N., Taliani C., Bradley D. D. C., Dos Santos D. A., Brédas J. L., Lögdlund M., Salaneck W. R.,\| Electroluminescence in conjugated polymers $\|$, in Nature, 397 (1999) 121.

[16] Fukuda M., Sawada K., Morita S., Yoshino K., N Novel characteristics of conducting poly(9-alkylfluorene), poly(9,9- dialkylfluorene) and poly(1,10-bis $\left(9^{\prime}-\right.$ alkylfluorenyl) alkane)\|, in Synthetic Metals, 41 (1991) 855.

[17] Xie W, Hou J and Liu S, - Blue and white organic light-emitting diodes based on 4,4-bis(2,2 diphenyl vinyl)-1,1-biphenyl -, $\quad$ in SemicondSciTechnol 18:L42 (2003).

[18] Li G., Shrotriya V., Huang J. S., Yao Y., Moriarty T., Emery K., Yang Y., -High-efficiency solution processable polymer photovoltaic cells by selforganization of polymer blends.\|, in Nature Mater., 4 (2005) 864.

[19] Tang C. W.,\| Hole injecting zone comprising porphyrinic compound between anode and luminescent zonell, in US Patent, (1982) 4356429.

[20] Tang C. W., VanSlyke, S. A.,॥ Organic electroluminescent diodes\|, in Appl. Phys. Lett., 51 (1987) 913.

[21] Kulkarni A. P., Tonzola C. J., Babel A., Jenekhe S. A.,lelectron transport materials for organic lightemitting diodes $\|$, in Chem. Mater., 16 (2004) 4556.

[22] Hung L. S., Chen C. H.,l Recent progress of molecular organic electroluminescent materials and devices॥, in Mater; Sc. Eng., R 39 (2002) 143.

[23] J. ĩmija, M.J. Maáachowski, J. ZieliЕ̌ski, M. Wacáawek, K. ĝciē̄ka,

-Organic materials for electronics\|, in ChemistryDidactics- Ecology-Metrology 11/1-2 (2006) 69-80 (in Polish).

[24] J.H. Burroughes, D.D.C. Bradley, A.R. Brown, R.N. Marks, K. Mackey, R.H. Friend, P.L. Burns, A.B. Holmes, $\|$ Lightemitting diodes based on conjugated polymers\|, in Nature 347 (1990) 539- 541.
[25] W. Y. Chou, S. T. Lin, H. L. Cheng, M. H. Chang, H. R. Guo, T. C. Wen, Y. S. Mai, J. B. Horng, J. B. Horng, C. W. Kuo, F. C. Tang,

C. C. Liao, and C. L. Chiu,-Polymer lightemitting diodes with thermal inkjet printed poly $(3,4-$ ethylenedioxythiophene): polystyrenesulfonate as transparent anodel, in Thin Solid Films, 515, 3718 (2007).

[26] Elschner, F. Jonas, S. Kirchmeyer, W. Lövenich, N. Koch, K. Fehse, M. Pfeiffer, K. Walzer, K. Leo, IDW-06, -High-Conductive PEDOT/PSS for ITOsubstitution in OLEDsl, in Proceedings of the 13th International Display Workshop, Otsu, Japan, December 6 - 8 (2006)

[27] Kulkarni A. P., Tonzola C. J., Babel A., Jenekhe S., A Electron transport materials for organic lightemitting diodes\|, in Chem. Mater., 16 (2004) 4556.

[28] Wu J., Agrawal M., Becerril H. A., Ba Z., Liu Z., Chen Y., Peumansssi P., Acs Nano, 4 ( Singh M., Chae H. S., Froehlich

J. D., Kondou T., Li S., Mochizuki A., Jabbour G. E., lorganic semiconductor devices via fermi level deepening at the metal organic interfacell, in Soft Matter, 5 (2009) 3002.

[29] T.K. Hatwar, J. Spindler, S.A. Van Slyke, -High performance tandem OLEDs for large area full colour AM displays and lighting applications\|, in Proceedings of the International Meeting

—Information Displayll IMID 2006 Daegu, 2006, 15821585 . 